\title{
Effects of Electromagnetic Fields on Human Beings and Electronic Devices
}

\author{
Binaya Kumar Jha \\ Department of Physics, Prithvi Narayan Campus, Tribhuvan University, Nepal \\ Correspondence: psbkrpix@gmail.com
}

\begin{abstract}
The electromagnetic energy is absorbed in some proportion in the human body and certainly has some effects. In this study, the electromagnetic radiations from electronic devices on the human and electronic devices on the human and electronic devices was investigated. The human head model was simulated and the results were compared with the results of the studies in the literature.
\end{abstract}

Keywords: electr omagnetic (EM) radiations (EMR), specific absorption rate (SAR), head model, Central Nervous System (CNS), Ionizing and Non-ionizing radiations.

\section{Introduction}

Electric and Electronic devices, wireless cellular telephones and other mobile personal communication services are the fastest growing field in the world. A certain amount of energy from radiation is absorbed and converted into heat (Thermal effect). It results about possible health effects of human exposure to electromagnetic energy. The athermal effects arising from exposure to radio frequencies (RF) leads to subtle effects on cells that could have an effect on cancer development or influences on electrically excitable tissue. It could influence the function of the brain and nervous tissue, and probably on the brain function, with particular emphasis on headaches and memory loss. The basic unit of exposure is expressed by the quantity called "specific absorption rate" (SAR). SAR is the time rate at which EM energy is absorbed by (dissipated in) an element of biological body mass in units of watts per kilogram (W/kg). The maximum local SAR depends on a large number of factors, such as : Design of the device, its operational frequency and antenna input power and orientation with respect to the human. The power absorbed by the tissues will produce a temperature rise that is dependent on the cooling mechanism of the tissues. when the thermoregulatory capability exceeds, tissue damage results. Some electromagnetic waves carry so much energy per quantum that they have the ability to break bonds between molecules. In the electromagnetic

spectrum, gamma rays are given off by radioactive materials, cosmic rays and x-rays carry this property and are called ionizing radiation. Fields whose quanta are insufficient to break molecular bonds are called non-ionizing radiation. Man made sources of EMfields are found at the relatively long wavelength and low frequency end of the electromagnetic spectrum and their quanta are unable to break chemical bonds. Mobile phones have non-ionizing radiation. Frequencies between about $30 \mathrm{KHz}$ and $300 \mathrm{GHz}$ are widely used for telecommunication, including broadcast radio and television, and comprise the radio frequency (RF) band. Cellular mobile phone services operate within the frequency ranges $872-960 \mathrm{MHz}$ and $1710-1875 \mathrm{MHz}$ waves at higher frequencies but within the RF-region.

The SAR can be applicable to mobile phones and it is a way of measuring the RF that is absorbed by the tissues. SAR testing on wireless phones is done at the maximum power output level for the phone.

SAR is defined as

$\mathrm{SAR}=\sigma \frac{\mathrm{Ei}^{2}}{\rho}=\mathrm{C}_{\mathrm{i}} \frac{\mathrm{dT}}{\mathrm{dt}}=\frac{\mathrm{J}^{2}}{\mathrm{f} \sigma}$

$\sigma=$ conductivity of the body tissue $\mathrm{s} / \mathrm{m}$

$\rho=$ density of the body tissue in $\mathrm{kg} / \mathrm{m}^{3}$

$E_{i}=r m s$ value of electric field in the tissue $v / m$ 
$\mathrm{C}_{\mathrm{i}}=$ Heat capacity of the body tissue in $\mathrm{J} / \mathrm{kgk}$

$\mathrm{T}=$ temperature

$\mathrm{J}=$ magnitude of induced current density in the body tissue $\mathrm{A} / \mathrm{m}^{2}$

\section{Safety and Standards}

There are two main exposure guidelines for RF radiation in Europe. The National Radiological protection Board (NRPB) in 1993 and International protection (ICNIRP) in 1998. The NRPB is based on the potential of RF radiation to cause illness or injury through heating of body tissues. The ICNIRP was designed to prevent illness and injury through heating effects shown in the table below:

\begin{tabular}{|c|c|c|c|}
\hline Tissue Region & $\begin{array}{c}\text { SAR limit (W/ } \\
\text { kg) }\end{array}$ & Mass (g) & $\begin{array}{c}\text { Time } \\
\text { (minutes) }\end{array}$ \\
\hline Whole body & $0.4(0.08)$ & - & 6 \\
\hline Head, Trunk & $10(2)$ & 10 & 6 \\
\hline Limbs & $20(4)$ & 10 & 6 \\
\hline
\end{tabular}

The brackets for general public exposure and unbracketed values for occupational exposure.

The table below gives the reference lends for public exposure to mobile communications frequencies.

\begin{tabular}{|c|c|c|c|}
\hline Frequencies & $\begin{array}{c}\text { Electric field } \\
\text { strength (V/m) }\end{array}$ & $\begin{array}{c}\text { Magnetic } \\
\text { field strength } \\
(\mathbf{A} / \mathbf{m})\end{array}$ & $\begin{array}{c}\text { Power } \\
\text { density } \\
\left(\mathbf{W} / \mathbf{m}^{2}\right)\end{array}$ \\
\hline $400-2000$ & $1.375 \sqrt{\mathrm{f}}$ & $0.0037 \sqrt{\mathrm{f}}$ & $\mathrm{f} / 200$ \\
\hline $2000-3000$ & 61 & 0.16 & 10 \\
\hline
\end{tabular}

\section{Experimental and Simulation result}

Maximum electric field values were measured from the front side very close to the mobile phones for different phones. The measurement was repeated for other sides.

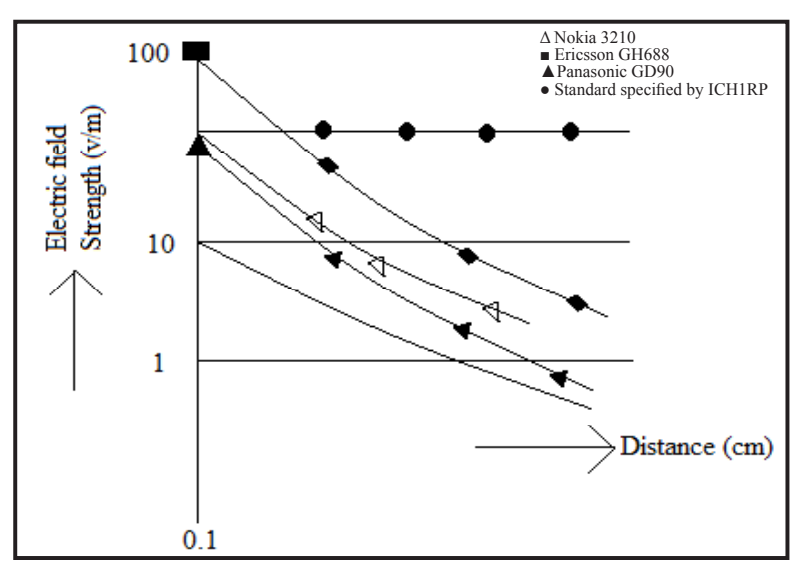

Among the mobile phones, Ericsson GH688 radiated the highest electric field upto $76 \mathrm{~V} / \mathrm{m}$. Panasonic Nokia 3210 radiated lower electric fields at the front side than backside.

\section{Conclusion}

The near electric field radiated from mobile phones has been evaluated. It was observed that electric fields radiated from mobile phones were two times higher during speaking that listening. However, the results obtained during contact with the base station much higher than the $42 \mathrm{~V} / \mathrm{m}$ that is the limit specified by the ICN/RP. It must be noted that, a max SAR value of $10.8 \mathrm{~W} / \mathrm{kg}$ gives rise to a temperature rise in the brain of about $0.931{ }^{\circ} \mathrm{C}$. The rate of absorption and the distribution of EMR energy is an organism depend on many factors, the dielectric composition (i.e. ability to conduct electricity) of the irradiated tissue e.g. bones with a lower water content, absorb less of the energy than muscles, the size of the object relative to the wavelength of EMR, shape, geometry and orientation of object and configuration of the radiation.

\section{References}

1. Bernavdi, P.S. Pisa, E. Puizzi, "Specific absorption Rate and Temperature Increase int eh Head of a cellular phone user". IEEE Transactions on Microwave Theory and Techniques W148. July 2000.

2. Nikita K.S. G.S. Stamatakos, "Analysis of the Interaction Between a Layered Spherical Human Head Model and a Finite Length Dipole". IEEE transactions on Microwave Theory and Techniques. W/48, Nov. 2000.

3. Celik C.G. "EM Effects of Mobile Phone on Human being". MS Thesis, Turkey 2001.

4. Battocletti J.H. "Electromagnetism, Man and the environment" Westwier, London 1976.

5. Tell R.A. "Broadcast Radiation How Safe is Safe IEEE Spectrum, Aug. 1972. 